Fifth International Conference on Sustainable Construction Materials and

Technologies. http://www.claisse.info/Proceedings.htm

\title{
EXPERIMENTAL INVESTIGATION ON THE BEHAVIOUR OF RECYCLED AGGREGATE CONCRETE
}

\author{
Robert Kovacs ${ }^{a}$, Rabee Shamass ${ }^{b}$, Vireen Limbachiya ${ }^{b}$, Mahmood Datoo ${ }^{c}$ \\ ${ }^{a} \mathrm{PhD}$ candidate in the Division of Civil and Building Services Engineering, School of Build \\ Environment and Architecture, London South Bank University, UK \\ ${ }^{\mathrm{b}}$ Lecturer in the Division of Civil and Building Services Engineering, School of Build \\ Environment and Architecture, London South Bank University, UK \\ ${ }^{c}$ Associate professor in the Division of Civil and Building Services Engineering, School of \\ Build Environment and Architecture, London South Bank University, UK
}

\begin{abstract}
The amount of construction and demolition waste has increased considerably over the last few decades due to growing construction industries. There has been an increasing trend toward the use of sustainable materials and reduce the consumption of nonrenewable natural resources. Recycling and reuse of demolition concrete in construction is one potential solution to minimise the natural resources. Recently the main use of recycled concrete aggregate (RCA) is for non-structural applications such as in road sub-bases. However, research studies suggest that the natural aggregates can be partially or fully substituted by RCA if well graded and good quality RCA is guaranteed. The RCA concrete has a lower elastic modulus, compressive and tensile strength, and ductility and greater water absorption than natural aggregate (NA) concrete. Furthermore, the age of the concrete used as RCA has a vital effect on the mechanical properties of the recycled aggregate concrete. However, adding steel fibres (SFs) into RCA mix may improve its mechanical properties. The purpose of this study is to evaluate the percentage of RCA replacement and the age of original concrete on the compressive and tensile strength RCA at 7-, 14- and 28- days. Furthermore, this research will investigate the effect of steel fibre percentage and hook geometry on the compressive and tensile strength of NA to anticipate the effect of steel fibres on the mechanical properties of concrete made from RCA. To achieve that, a number of concrete cubes, cylinders with different percentage of RCA replacements and 3D and 5D hooked end SFs are casted to assess the compressive and tensile strength.
\end{abstract}

Keywords: Compressive strength of concrete, concrete demolition waste, hooked end steel fibres, recycled concrete aggregates, tensile strength of concrete. 


\section{INTRODUCTION}

Recently, there has been an increasing trend towards the use of sustainable materials and to reduce the consumption of non-renewable natural resources. The Committee on Climate Change (CCC) have just recently announced that the UK 'can cut emissions to nearly zero' by 2050 . In order to have such drastic changes, the UK construction industry that accounts for almost $47 \%$ of the total $\mathrm{CO}_{2}$ emissions emitted in the UK has a crucial role to play. Currently, the construction industry in the UK uses more than 165 million tonnes of natural resources every year and produces around 109 million tonnes of demolition waste. From this waste, 60 million tonnes arise solely from demolished concrete (Damdelen, 2018). Concrete is the most used material in the construction industry and due to the sheer quantity of natural resources required for production, it is one of the most unsustainable materials due to its high embodied energy. As demolition waste can be used to replace the natural resources in the production of concrete, this region of research is a key area to develop, as it can reduce the quantity of waste sent to landfill as well as reduce the quantity of natural resources used on a construction site. The aim of this paper is to analyse the impact of recycled concrete aggregate (RCA) as a replacement for both natural fine and coarse aggregate. As well as this, the paper will look at the impact of steel fibres (SFs) to review the potential impact of using RCA in structural elements.

Researchers have investigated the use of RCA in the production of concrete. Studies have proven that using RCA is a potential solution to minimize the consumption of natural aggregate (NA) resources if well graded and good quality RCA are guaranteed (Marie and Quiasrawi, 2012). Ignjatovic et al. (2013) tested cubes and beams specimens made from $100 \%$ NA, $100 \%$ RCA, and 50\% RCA. They found that the type of aggregate did not make significant effect on flexural behaviour of the beams; however, 3\% more cement is required for RCA to produce the same compressive strength of concrete cubes with NA. Folino and Xargay (2014) pointed out that it is important that the crushed concrete has the right aggregate particle distribution as the NA to achieve the well-packed concrete and helps the concrete to flow and fill the formwork completely. One of the key advantages to take note of with the use of RCA is the economic advantage. As Anandaraj et al (2018) stated, the prices of steel reinforcement, cement, sand, granite, etc. becoming more than double in price are making sustainable techniques more common because of their economic value. However, there are many disadvantages of using RCA. Studies concluded that the RCA has higher water absorption, higher porosity, greater shrinkage and also lower relative density than the NA (Folino and Xargay, 2014 and Tahar Zine-el-abidine et al, 2017). Furthermore, the compressive strength and elastic modulus of recycled aggregate concrete (RAC) decrease with increasing the RCA contents (Xiao et al., 2005). However, Gómez-Soberón, José (2002) reported that for 30\% RCA the strength was not that significant although when replacement levels increase to $100 \%$ there is a lower compressive strength. Additionally, more appreciable distributed damages were observed in the concrete with greater contents of RCA under uniaxial compression (Folino and Xargay, 2014). 
Due to these shortcomings and the lack of research on RCA, there has been discouragement by some researchers to use of RCA in structural elements. On the other hand, current research studies have shown that adding steel fibre and RCA in a mix will improve its mechanical properties and quality. For instance, it was found that combination of $0.75 \%$ of SFs and $25 \%$ of RCA increases the mechanical strength of the concrete and modifies the fracture process (Carneiro et al., 2014). Moreover, Gao et al. (2017) found that addition of SFs can effectively improve the shear strength and shear toughness of RAC. Research studies in the literature insufficiently address the combination of both RCA and SFs. Recently, Senaratne et al (2016) conducted nine simply-support concrete beams subjected to point load. SFs volume fractions were $0 \%$, $0.3 \%$, and $0.6 \%$ while RCA ratios were $0 \%, 30 \%$ and $100 \%$. They found that the optimum combination was $30 \%$ RCA replacement with the addition of $0.6 \%$ SFs.

\section{RECYCLED AGGREGATE SOURCING}

Tsoumani et al. (2005) found that the mechanical properties of concrete made from recycled aggregates sourced from construction and demolition waste are weaker than those samples sourced from demolished concrete from the university laboratory. This is due to the fact that the concrete waste made from the laboratory was new and originally made with better workmanship than it was made on building site. Folino and Xargay (2014) casted concrete samples sourced from laboratory concrete waste and found that recycled aggregate concrete made from these aggregates were higher in compression, shear and tension strength but lower than concrete made from natural coarse aggregates NCA.

In this research it is important to use such an aggregate that is readily available from a demolition contractor and is an inexpensive and competitive replacement for NA. It is economically essential to use a recycled aggregate that is cheap, easy to source and close to transport.

The demolition concrete waste used in this study was chosen from an old concrete building. This old concrete is considered a representative concrete of many buildings in the UK since most of the construction in this period will be demolished in future to give space for new buildings. The concrete was pre crushed on site with a long reach 360 excavator to $250 \mathrm{~mm}$ maximum size and feed to TEREX J-1170 mobile jaw crusher to produce $20 \mathrm{~mm}$ crashed concrete aggregates, as seen in the Figure 1. The jaw crusher used powerful magnets to recycle ferrous metals like reinforcement bars.

The aggregate was further sieved using a $20 \mathrm{~mm}$ sieve to ensure that the particle size of recycled concrete aggregates RCA is no more than $20 \mathrm{~mm}$ (See Figure 2). The resulting RCA being sieved in $20 \mathrm{~mm}$ sieve were used in this study to as both coarse and fine RCA particles.

Another recycled concrete aggregates from RC40/50 waterproof new concrete waste was used in this study to investigate the effect of resource of RCA and its age on the mechanical properties of concrete. This concrete was broken up by jackhammering and sieved to $20 \mathrm{~mm}$ maximum size, as seen in the Figure 3. For this new RCA (NRCA) 
5th International Conference on Sustainable Construction Materials \& Technologies

Kingston Hill campus, Kingston Hill, Kingston upon Thames, Surrey KT2 7LB 14 - July-17 July 2019

it was noted that it contained much fewer fine particles than the RCA produced from old concrete.

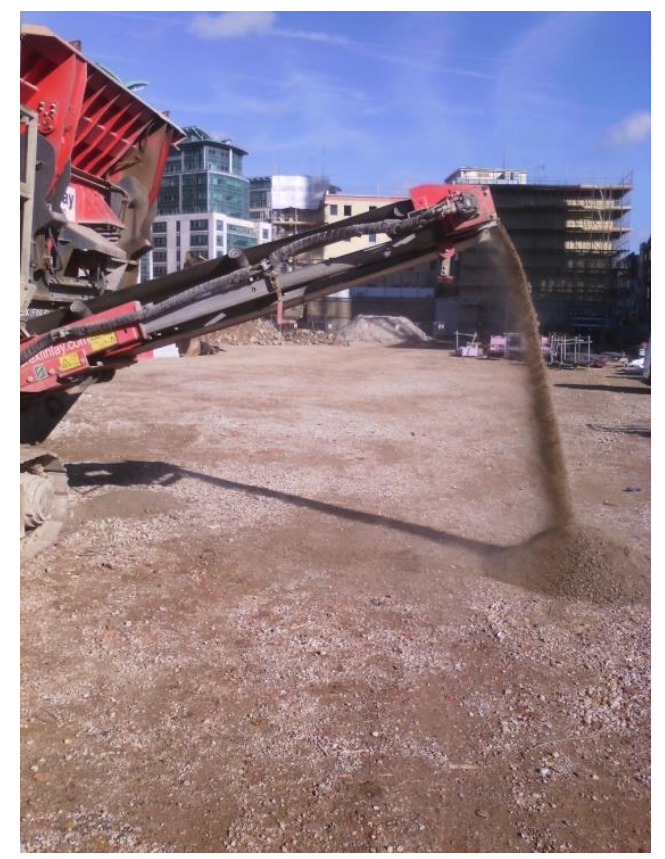

Figure 1: Crushing concrete aggregates on site

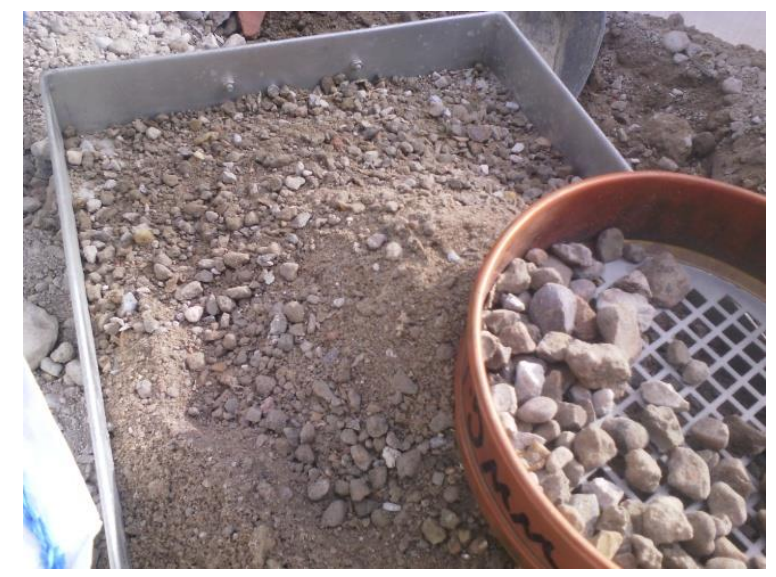

Figure 2: Sieving crushed concrete particles into 20mm maximum size 


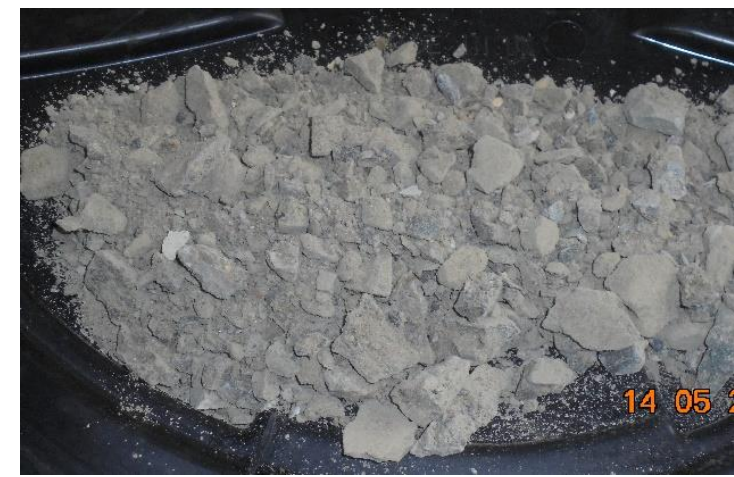

(a)

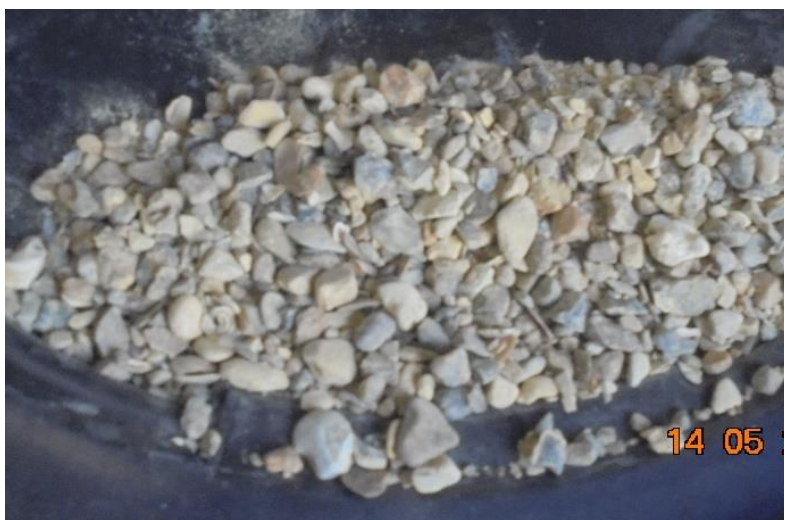

(c)

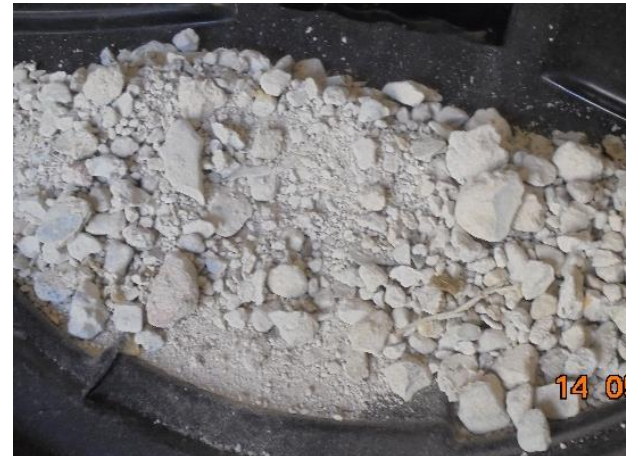

(b)

Figure 3: (a) NRCA; (b) RCA; and (c) NCA used in this study

\section{RECYCLED AND NATURAL AGGREGATES PROPERTIES}

The particle size distribution curves for RCA, natural coarse aggregates NCA and natural sand was established in the Figure 4 and compared to the particle distribution of upper and lower limits according to BS 882:1992. It worth mentioning that NCA supplied in separate bulk bags consists of $1 \%$ 0-5mm aggregates and $95 \% 5-14 \mathrm{~mm}$ coarse aggregate. The curve for RCA is slightly close to the upper limit due to the higher number of finer particles especially below $5 \mathrm{~mm}$. 


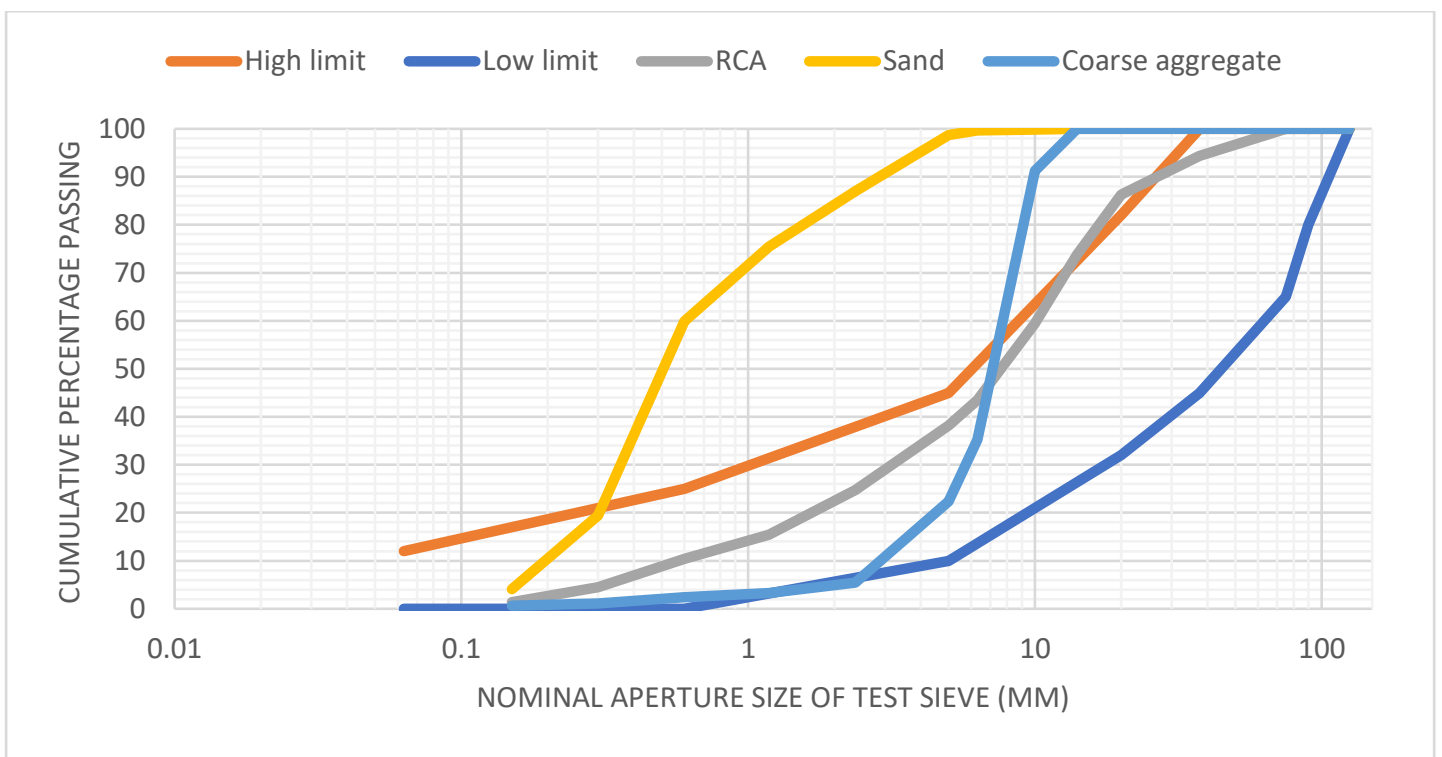

Figure 4: Particle size distribution

Table 1 illustrates the moisture content of the aggregates and it can be noted that the RCA has higher moisture contents than the sand and coarse aggregates due to the fact that the water sits in the pores of the existing mortar attached to the stone particles of the aggregate. Ferreira et al. (2010) stated that the properties of concrete made from RCA may be affected by the RCA's properties, especially the water absorption. The study found that the mixing water compensation method can be used when mixing and casting the concrete made from RCA. Therefore, in this study the absorption capacity was obtained for the RCA, the case at which the aggregates are in the saturated surface dry (SSD) state. It is found that the absorption is capacity $11 \%$.

Saturated surface dry densities (SSD) for all aggregates were measured and their values are shown in the Table 2. The RCA aggregate has slightly smaller SSD than the sand and coarse aggregates due to the entrapped air voids within the larger particles and due to the small amount of impurities such as timber and plastic.

Table 1: Moisture contents

\begin{tabular}{|l|l|}
\hline Aggregates & Moisture contents (\%) \\
\hline RCA & 9.47 \\
\hline Sand & 4.44 \\
\hline Coarse aggregates & 3.25 \\
\hline
\end{tabular}


Table 2: the SSD for the aggregates

\begin{tabular}{|l|l|}
\hline Aggregates & Saturated Surface Dry Density SSD \\
\hline Sand & 2.416 \\
\hline RCA & 2.411 \\
\hline Coarse aggregates & 2.213 \\
\hline NRCA & 2.429 \\
\hline
\end{tabular}

\section{CONCRETE MIX DESIGN}

A C50 concrete mix was designed using BRE Concrete Mix Design. The obtained SSD of the aggregates was used in the concrete mix design where the total volume of the recycled aggregates plus natural aggregates in one cubic meter of concrete was kept constant for all concrete specimens.

The moisture contents of RCA, sand and NCA can be changed due to unpredicted weather. To avoid the discrepancies in the moisture contents and their effect on the properties of produced concrete, the RCA material was dried in oven for 24 hours and both NCA and sand was dried inside the laboratory (it took 7 days to fully dry the aggregates). This is to ensure that both types of aggregates were dried at the time of concrete mixing. After a number of trials, it is decided to mix the RCA with $11 \%$ water for 10 mins to achieve aggregates with SSD state and acceptable workability (about $200 \mathrm{~mm}$ slump) then sand, cement, coarse aggregate and free water were added and mixed for 5 minutes.

Five mixes were prepared for concrete compression and split cylinder test, namely concrete with natural aggregate acting as a control sample, concrete mix with $25 \%$, $50 \%$ and $100 \%$ RCA and concrete mix with $100 \%$ NRCA. Additionally, four more mixes were prepared to study the effect of adding steel fibres and their hook geometry on the compressive and tensile strength of concrete made from NA. $0.5 \%$ and $1 \% 3 \mathrm{D}$ hooked end steel fibres and $0.5 \%$ and $1 \%$ 5D hooked end steel fibres were added into wet concrete mix and mixed for further 5 minutes. The aspect ratio of the used fibres is 65 and the length is $60 \mathrm{~mm}$. Three samples of cubes and three cylinders of 7-, 14and 28-days tests were prepared. The moulds were removed on the following day and the concrete samples were stored in a curing tank at $20^{\circ} \mathrm{c}$. Table 3 shows the concrete mixes in $\mathrm{kg} / \mathrm{m}^{3}$.

Table 3: Concrete mixes

\begin{tabular}{|c|c|c|c|c|c|c|c|}
\hline $\begin{array}{c}\text { Concrete } \\
\text { mix }\end{array}$ & Cement & Sand & RCA & NCA & $\begin{array}{c}\text { SSD } \\
\text { Water }\end{array}$ & $\begin{array}{c}\text { Free } \\
\text { Water }\end{array}$ & $\begin{array}{c}\text { Steel } \\
\text { Fibre }\end{array}$ \\
\hline NA & 575 & 418.5 & & 976.5 & & 230 & \\
\hline RCA25 & 575 & 313.88 & 319.84 & 732.38 & 39.98 & 230 & \\
\hline RCA50 & 575 & 209.25 & 639.69 & 488.25 & 79.96 & 230 & \\
\hline RCA100 & 575 & & 1279.4 & & 159.92 & 230 & \\
\hline
\end{tabular}




\begin{tabular}{|c|c|c|c|c|c|c|c|}
\hline NRCA100 & 575 & & 1318.7 & & & 260 & \\
\hline $\begin{array}{c}\text { NA } \\
0.5 \% 3 D\end{array}$ & 575 & 418.5 & & 976.5 & & 230 & 39.25 \\
\hline NA 1\%3D & 575 & 418.5 & & 976.5 & & 230 & 78.5 \\
\hline $\begin{array}{c}\text { NA } \\
0.5 \% 5 D\end{array}$ & 575 & 418.5 & & 976.5 & & 230 & 39.25 \\
\hline NA 1\% 5D & 575 & 418.5 & & 976.5 & & 230 & 78.5 \\
\hline
\end{tabular}

\section{COMPRESSIVE AND TENSILE STRENGTH OF CONCRETE}

\section{The Effect of RCA Replacement Percentage and RCA Source}

The effect of RCA replacement percentage and the source of RCA on the mechanical properties of concrete, mainly the compressive and tensile strength of concrete at 7, 14 and 28 are investigated. The failure mode in compression and tension of the NA mix is shown in the Figure 5.
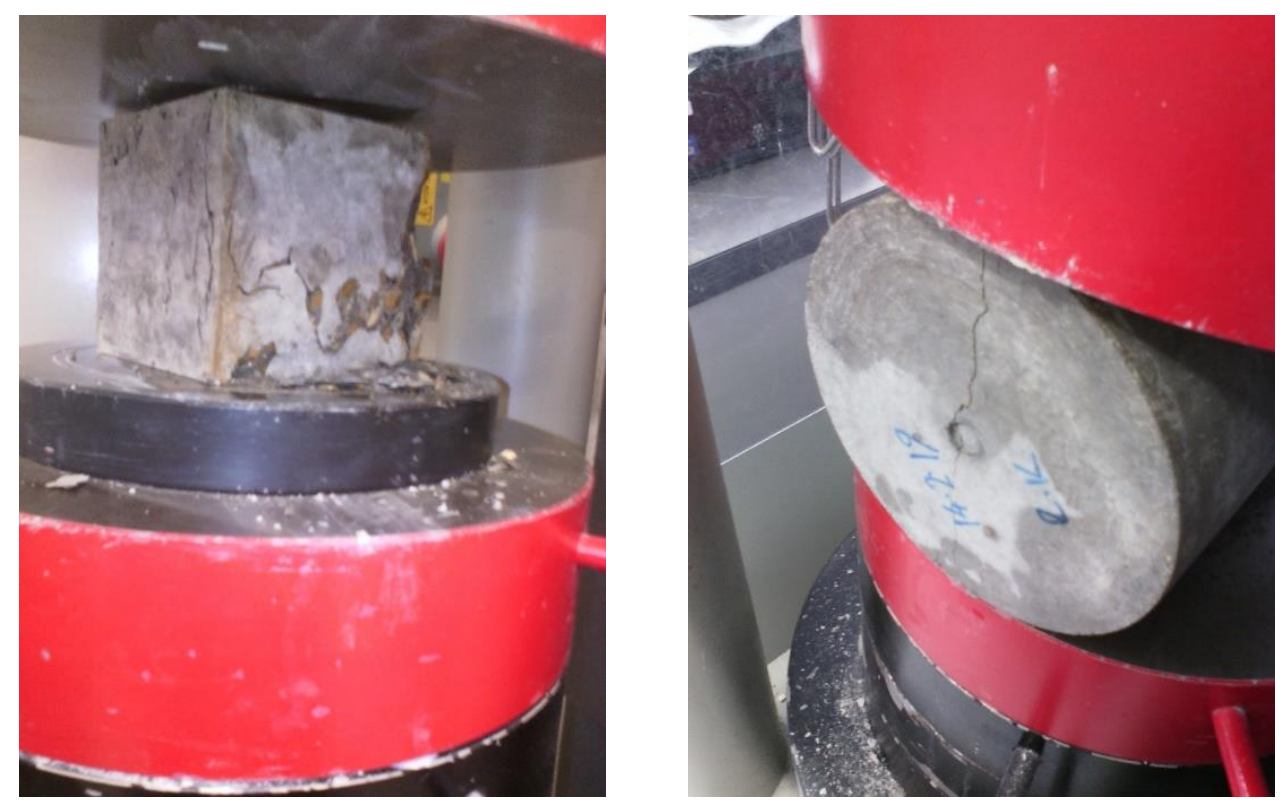

Figure 5: Samples in testing machine

Figures $6 \mathrm{a}$ and $6 \mathrm{~b}$ illustrate the compressive and tensile strength, respectively, for NA, RCA25, RCA50, RCA100 and NRCA100 concrete at 7, 4 and 28 days. It can be observed that both the compressive tensile strength of concrete decrease by increasing the content of RCA replacement. At 7 days, the compressive strength of concrete made with $25 \%, 50 \%$ and $100 \%$ RCA replacement declines by $25 \%, 32 \%$ and $56 \%$, respectively, compared to control concrete samples. At 14 days, the compressive strength for the same concrete mixes reduce by $18 \%, 32 \%$ and $51 \%$. Furthermore, the compressive strength of concrete at 28 days reduce by $11.5 \%, 28 \%$ and $49 \%$ for concrete made with $25 \%, 50 \%$ and $100 \%$ RCA replacement. Additionally, the tensile strength of concrete made with $25 \%, 50 \%$ and $100 \%$ RCA replacement decline by 
$15 \%, 28 \%$ and $30.5 \%$, respectively. Furthermore, the tensile strength of concrete at 28 days reduce by $8 \%, 18 \%$ and $28 \%$ for concrete made with $25 \%, 50 \%$ and $100 \%$ RCA replacement.

Regarding to concrete samples made from $100 \%$ new concrete replacement (NRCA100), the compressive strength at 28 day reduces by only $1.7 \%$ and the tensile strength increase by $10.4 \%$ while the concrete samples made from $100 \%$ replacement of old concrete aggregates (RCA100), the compressive and tensile strength reduce by $49 \%$ and $28 \%$, respectively. This is due to the fact that the RCA is sourced from an old concrete high-rise building which was over 60 years old while NRCA was sourced from a 1-year old waterproof concrete. It was appreciated that 60-70 years ago the concrete technology was not as advanced as now, however the RCA represents an average concrete building in UK and London to be demolished for new development. The mortar attached to the stone RCA particles lead the failure through the interface line (see Figure 7), while failure line of NRCA100 lead through many basalt particles rather than the old-new cement paste interface, which suggest the old paste bond is strong as the new mortar paste.

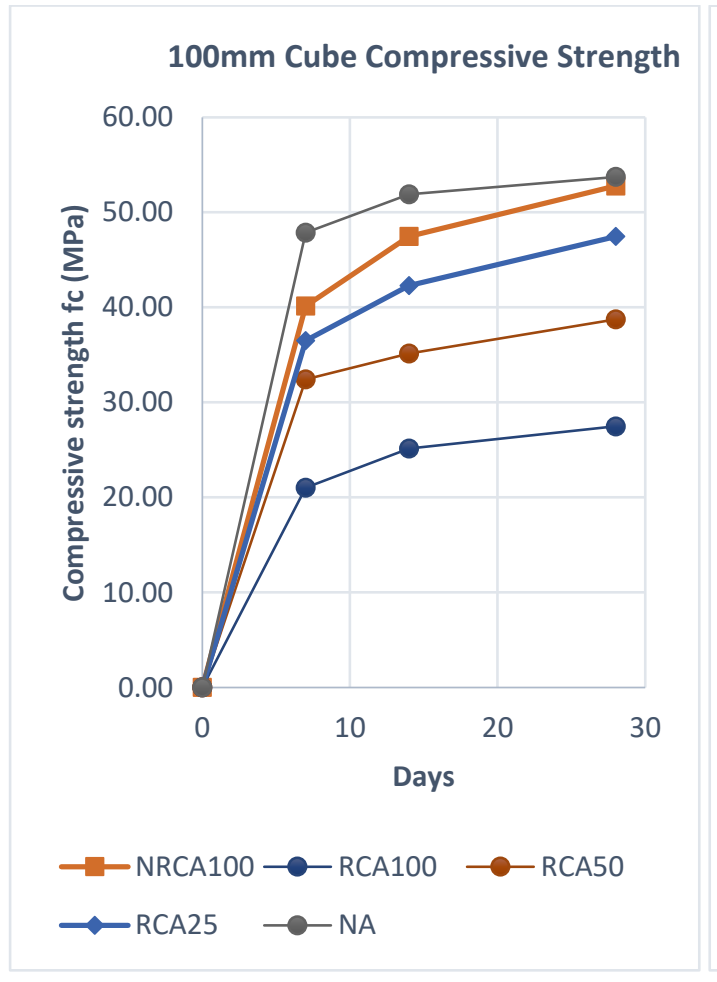

(a)

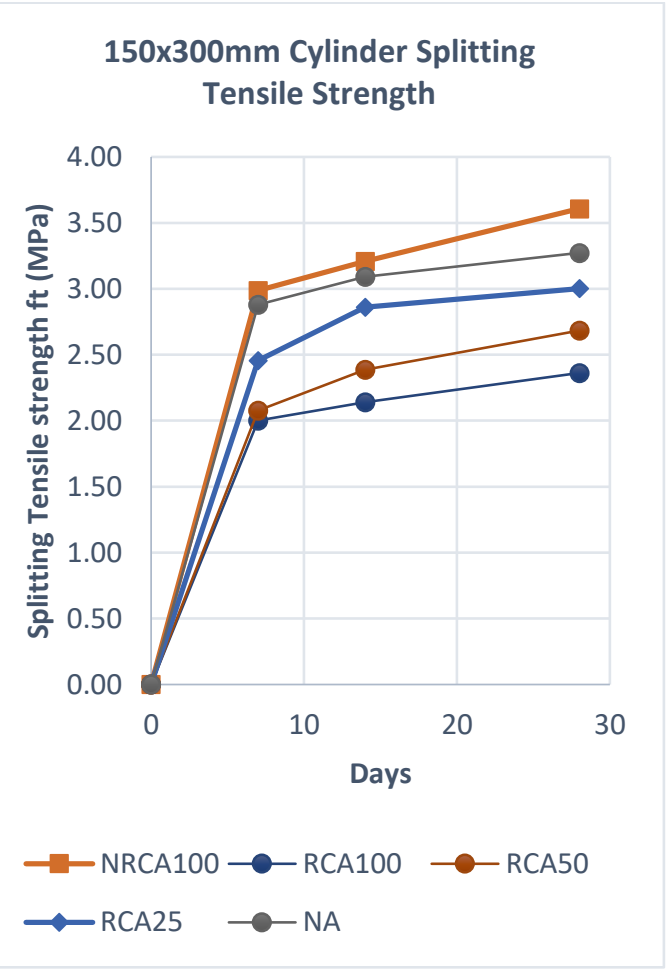

(b)

Figure 6: Test results for (a) compressive strength; and (b) tensile strength 


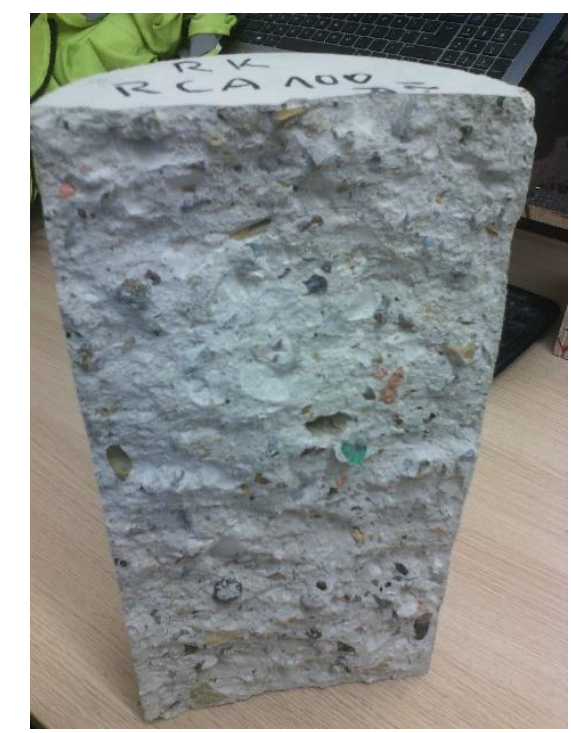

Figure 7: Failure surface of RCA100

\section{EFFECT OF STEEL FIBRES PERCENTAGE AND HOOK GEOMETRY}

The effect of steel fibres percentage and hook geometry on the compressive tensile strength of concrete casted from natural coarse aggregates are presented in the Table 6. The reason for conducting these tests is to anticipate the effect of steel fibres on the mechanical properties of concrete made from RCA. Figure 8 represents the failure of steel fibres reinforced concrete in tension and compression.

Table 4: the compressive and tensile strength of steel fibre reinforced concrete

\begin{tabular}{|l|c|c|c|c|c|c|}
\hline & \multicolumn{3}{|c|}{ Compressive strength Mpa } & \multicolumn{3}{|c|}{ Tensile strength Mpa } \\
\hline Days & 7 & 14 & 28 & 7 & 14 & 28 \\
\hline NA & 47.9 & 51.9 & 53.7 & 2.88 & 3.09 & 3.27 \\
\hline NA 0.5\%3D & 47.4 & 54.6 & & 3.86 & 3.89 & \\
\hline NA 1\%3D & 48.9 & 56.2 & 63.3 & 4.84 & 5.45 & \\
\hline NA 0.5\% 5D & 49.9 & 56.5 & 63.2 & 4.12 & 4.86 & 4.80 \\
\hline NA 1\%5D & 52.2 & 57.4 & 64.5 & 5.98 & 6.43 & 6.98 \\
\hline
\end{tabular}

Based on the results presented in the Table 4, the following observations are found:

- The steel fibres slightly improve the compressive strength of concrete and significantly improve the tensile strength of concrete at 7 days. For examples, using 5D hooked end steel fibres in the concrete control mix, the compressive strength of concrete improves from $4.2 \%$ to $9 \%$ and the tensile strength of concrete improve from $43 \%$ to $107.6 \%$ when the steel fibres percentage increase from $0.5 \%$ to $1 \%$. 
- At 28 days, both compressive and tensile strength of concrete improve by increasing the steel fibres percentage. For instance, using 5D steel fibres in the concrete control mix, the compressive strength of concrete improves from $17.7 \%$ to $20 \%$ and the tensile strength of concrete improves from $48.6 \%$ to $113.5 \%$ when the steel fibres percentage increase from $0.5 \%$ to $1 \%$.

- The hook geometry of steel fibres (3D and 5D hooked end steel fibres) has a slight effect on the compressive strength of concrete and a significant effect on the tensile strength of concrete. If $1 \%$ fraction volume of steel fibres is added into the concrete control mix, the 3D hooked end fibres improve the compressive and tensile strength at 7 days by $2.1 \%$ and $68.1 \%$, respectively, and the 5D hooked end fibres improve the compressive and tensile strength at 7 days by $9 \%$ and $107.6 \%$, respectively. Additionally, $1 \%$ of 3D hooked end steel fibres improves the compressive strength of concrete after 28 days by $18 \%$ and $1 \%$ of $5 \mathrm{D}$ hooked ends steel fibres improves the compressive strength of concrete by $20 \%$.
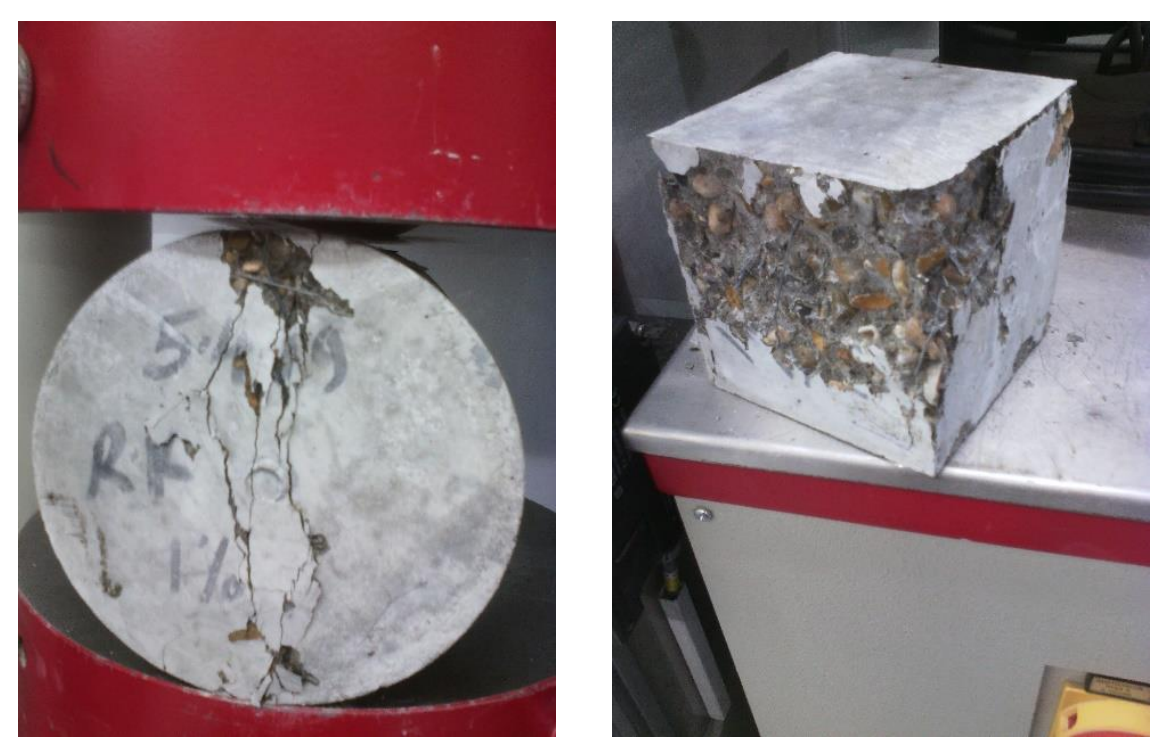

Figure 8: Failure mode of steel fibre reinforced concrete in tensile and compression

\section{CONCLUSION}

- The aim of this study was to review the impact of RCA, the difference between RCA and NRCA and impact of 3D and 5D hooked end steel fibres.

- Results showed that for at all ages, as the percentage of RCA increased the compressive and splitting tensile strength decreased. It is assumed that the decrease in strength is occurring due to the high SSD and particle distribution of RCA resulting in a mix in which the aggregates absorb a greater quantity of water which would be required for the cement hydration and greater final particles which results in uneven grading and therefore lower strengths. 
- When comparing RCA mix to the NRCA mix it can be seen that there is a dramatic improvement in the performance. The enhancement in strength properties was due to the failure occurring through the aggregate in NRCA instead of the old cement paste in RCA.

- When reviewing the impact of SFs it could be seen that the addition of 3D and 5D hooked end fibres increased both the compressive and splitting tensile strengths. 5D hooked end samples due to the geometry had a significant impact on the splitting tensile when compared to 3D and NA samples.

\section{ACKNOWLEDGMENT}

The authors would like to thank Keltbray Group for supplying the recycled concrete aggregates and would like to thank Bekaert Bradford UK Limited for supplying the 3D and 5D hooked end steel fibres for London South Bank University Laboratory. Furthermore, we would like to thank the technician Graham Bird for his continuous support at the Laboratory.

\section{REFERENCES}

Anandaraj, S., Rooby, J., Awoyera, P. O., \& Gobinath, R. 2018. Structural distress in glass fibre-reinforced concrete under loading and exposure to aggressive environments.

Construction and Building Materials, 1-9.

BSI. (2014). BS EN 1992-1-1 General rules and rules for buildings.

Carneiro, J.A., Lima, P.R.L., Leite, M.B. and Toledo Filho, R.D., 2014. Compressive stressstrain behavior of steel fiber reinforced-recycled aggregate concrete. Cement and concrete composites, 46, pp.65-72.

Damdelen, O. 2018. Investigation of 30\% recycled coarse aggregate content in sustainable concrete mixes. Construction and Building Materials, 184, 408-418.

Ferreira, L., De Brito, J. and Barra, M., 2011. Influence of the pre-saturation of recycled coarse concrete aggregates on concrete properties. Magazine of Concrete Research, 63(8), pp.617-627.

Folino, P. and Xargay, H., 2014. Recycled aggregate concrete-mechanical behavior under uniaxial and triaxial compression. Construction and Building Materials, 56, pp.21-31

Gao, D., Zhang, L. and Nokken, M., 2017. Mechanical behavior of recycled coarse aggregate concrete reinforced with steel fibers under direct shear. Cement and Concrete Composites, 79, pp.1-8.

Gómez-Soberón, J. M. V. (2002). Porosity of recycled concrete with substitution of recycled concrete aggregate: An experimental study. Cement and Concrete Research, 32(8), 13011311. 
Ignjatović, I.S., Marinković, S.B., Mišković, Z.M. and Savić, A.R., 2013. Flexural behavior of reinforced recycled aggregate concrete beams under short-term loading. Materials and structures, 46(6), pp.1045-1059.

Ithurralde, G. (1989). La perméabilité vue par le maître d'ouvrage Supérieure. Cachan: Colloque Béton à hautes performances (in french). Ecole Normale .

Marie, I. and Quiasrawi, H., 2012. Closed-loop recycling of recycled concrete aggregates. Journal of Cleaner Production, 37, pp.243-248.

S.B. Marinković et al., I. I. (2014). Life cycle assessment (LCA) of concrete made using recycled concrete or natural aggregates. Eco-efficient Construction and Building Materials .

Senaratne, S., Gerace, D., Mirza, O., Tam, V.W. and Kang, W.H., 2016. The costs and benefits of combining recycled aggregate with steel fibres as a sustainable, structural material. Journal of Cleaner Production, 112, pp.2318-2327.

Tahar, Z. el abidine, Ngo, T. T., Kadri, E. H., Bouvet, A., Debieb, F., \& Aggoun, S. (2017). Effect of cement and admixture on the utilization of recycled aggregates in concrete.

Tsoumani, A.A., Barkoula, N.M., Matikas, T.E., 2015. Recycled aggregate as structural material, Waste and Biomass Valorization, 6 883-890. 